\title{
KAITAN MAKROSOMIA DENGAN DIABETES MELITUS GESTASIONAL DI BAGIAN OBSGIN BLU RSUP PROF. DR. R. D. KANDOU MANADO PERIODE SEPTEMBER 2012-SEPTEMBER 2013
}

\author{
${ }^{1}$ Arlia Oroh \\ ${ }^{2}$ Maria Loho \\ ${ }^{2}$ Suzanna Mongan \\ ${ }^{1}$ Kandidat Skripsi Fakultas Kedokteran Universitas Sam Ratulangi Manado \\ ${ }^{2}$ Bagian Obstetri dan Ginekologi Fakultas Kedokteran Universitas Sam Ratulangi Manado \\ Email: arliamonicaoroh@ymail.com
}

\begin{abstract}
Gestasional diabetes mellitus in mother is an important risk factor for developing fetal macrosomia. Gestational diabetes mellitus is defined as glucose intolerance of variable degree with onset or first recognition during pregnancy. The prevalence of gestational diabetes mellitus in Indonesia is $1.9 \%-3.6 \%$ of pregnancies in general. The prevalence of gestational diabetes is strongly related to the patient's race and culture. Prevalence rates are higher in black, Hispanic, Native American, and Asian women than in white women. This was an analytical study with a case control design by using medical records in Prof. Dr. R. D. Kandou General Hospital Manado period September 2012-2013. The results showed that there was no relationship between macrosomia with gestational diabetes mellitus. Gestational diabetes mellitus is a risk factor for having a macrosomia baby. Risk factors for gestational diabetes mellitus and macrosomia are also widely available on the subjects include age $>35$ years, obesity and multiparity.
\end{abstract}

Keywords: macrosomia, gestational diabetes mellitus, diabetes melitus

\begin{abstract}
Abstrak: Diabetes melitus gestasional (DMG) pada ibu merupakan faktor risiko yang penting dalam perkembangan makrosomia fetus. DMG merupakan intoleransi karbohidrat dengan derajat yang bervariasi dengan onset atau diketahui pertama kali selama kehamilan berlangsung. Prevalensi DMG di Indonesia sebesar 1,9\%-3,6\% pada kehamilan umumnya. Prevalensi ini sangat berhubungan dengan ras dan etnis. Angka prevalensi lebih tinggi pada wanita negro, hispanik, native American, dan Asia dibandingkan dengan wanita kulit putih. Penelitian ini menggunakan metode studi analitik dengan desain studi kasus kontrol melalui rekam medik di RSUP Prof. Dr. R. D. Kandou Manado periode September 2012-2013. Hasil penelitian menunjukkan bahwa tidak terdapat kaitan antara makrosomia dengan DMG. DMG merupakan faktor resiko melahirkan bayi makrosomia. Faktor risiko DMG dan makrosomia juga banyak terdapat pada subjek antara lain usia $>35$ tahun, obesitas dan multiparitas.
\end{abstract}

Kata kunci: makrosomia, DMG, diabetes melitus

Istilah makrosomia digunakan untuk menggambarkan fetus atau bayi yang dengan ukuran yang lebih besar dari ukuran normal. Berat badan lahir lebih dari 4000 gram merupakan patokan yang sering digunakan dalam mendefinisikan makro- somia. ${ }^{1}$ Semua bayi dengan berat badan 4000 gram atau lebih tanpa memandang umur kehamilan dianggap sebagai makrosomia. $^{2}$

Beberapa faktor risiko yang berhubungan dengan makrosomia fetus 
diantaranya obesitas, diabetes melitus gestasional dan diabetes melitus tipe 2, orang tua berbadan besar, kehamilan lewat waktu dan multiparitas. Diabetes melitus gestasional (DMG) pada ibu merupakan faktor risiko yang penting dalam perkembangan makrosomia fetus. ${ }^{1-3}$ Insidensi diabetes melitus gestasional meningkat dengan meningkatnya berat badan bayi $>4000$ gram. $^{1}$

Prevalensi prediabetes di Indonesia pada tahun 2007 sebesar 10\% sedangkan prevalensi DMG di Indonesia sebesar 1,9\%-3,6\% pada kehamilan umumnya. ${ }^{4}$ Prevalensi DMG sangat berhubungan dengan ras dan etnis. Angka prevalensi lebih tinggi pada wanita negro, hispanik, native American, dan Asia dibandingkan dengan wanita kulit putih. ${ }^{5}$ Berdasarkan uraian di atas maka penulis tertarik untuk meneliti apakah ada kaitan makrosomia dengan DMG di RSUP Prof. Dr. R. D. Kandou Manado yang tergolong ras Asia.

\section{METODE PENELITIAN}

Penelitian ini menggunakan metode studi analitik dengan desain studi kasus kontrol melalui rekam medik di RSUP Prof. Dr. R. D. Kandou Manado periode September 2012-2013. Subjek penelitian yaitu populasi kasus dan populasi kontrol. Catatan rekam medic yang digunakan ialah pasien yang melahirkan selama periode September 2012 - September 2013.

Populasi kasus terdiri dari seluruh ibu yang melahirkan bayi makrosomia di Bagian Obsgin BLU RSUP Prof. Dr. R. D. Kandou Manado periode September 2012 September 2013. Populasi kontrol terdiri dari seluruh ibu yang tidak melahirkan bayi makrosomia di bagian Obsgin BLU RSUP Prof. DR. R. D. Kandou Manado periode September 2012 - September 2013. Variabel penelitian ialah diabetes melitus gestasional dan makrosomia.

\section{HASIL PENELITIAN}

Pengambilan sampel dilakukan di Bagian Rekam Medik BLU RSUP Prof. Dr. R. D. Kandou Manado dengan jumlah sampel 100 orang dimana 50 orang merupakan kelompok kasus (makrosomia) dan 50 orang kelompok kontrol (tidak makrosomia).

Pada variabel usia, pendidikan dan status pernikahan sesuai Tabel 1 didapatkan bahwa ibu hamil yang melahirkan bayi makrosomia (kelompok kasus) paling banyak berusia $>35$ tahun, sebaliknya pada kelompok kontrol usia >35 tahun merupakan usia tersedikit. Pendidikan SMA merupakan pendidikan terbanyak untuk kedua kelompok, begitu pula dengan status pernikahan dimana kebanyakan ibu hamil berstatus menikah pada kedua kelompok. Kelompok kasus kebanyakan merupakan multipara dan tergolong obesitas sedangkan pada kelompok kontrol paling banyak nulipara dan overweight.

Tabel 1. Karakteristik Responden

\begin{tabular}{|c|c|c|c|c|}
\hline & \multicolumn{2}{|c|}{$\begin{array}{c}\text { Kelompok } \\
\text { Kasus }\end{array}$} & \multicolumn{2}{|c|}{ Kelompok Kontrol } \\
\hline Usia & Jumlah & $\%$ & Jumlah & $\%$ \\
\hline$<20$ tahun & 2 & 4 & 9 & 18 \\
\hline 20-25 tahun & 10 & 20 & 13 & 26 \\
\hline 26-30 tahun & 13 & 26 & 10 & 20 \\
\hline 31-35 tahun & 8 & 16 & 12 & 24 \\
\hline >35 tahun & 17 & 34 & 6 & 12 \\
\hline \multicolumn{5}{|l|}{ Pendidikan } \\
\hline Tidak Tamat SD & 0 & 0 & 0 & 0 \\
\hline Tamat SD & 3 & 6 & 5 & 10 \\
\hline Tamat SMP & 3 & 6 & 5 & 10 \\
\hline Tamat SMA & 42 & 84 & 40 & 80 \\
\hline Akademik/D3 & 0 & 0 & 0 & 0 \\
\hline $\begin{array}{l}\text { Perguruan Tinggi } \\
\text { (S1/S2/S3) }\end{array}$ & 2 & 4 & 0 & 0 \\
\hline \multicolumn{5}{|l|}{ Status Pernikahan } \\
\hline Menikah & 39 & 78 & 43 & 86 \\
\hline Tidak Menikah & 11 & 22 & 7 & 14 \\
\hline \multicolumn{5}{|l|}{ Paritas } \\
\hline Nulipara $(<1)$ & 1 & 2 & 22 & 44 \\
\hline Primipara (1) & 12 & 24 & 14 & 28 \\
\hline Multipara (2-4) & 36 & 72 & 14 & 28 \\
\hline $\begin{array}{l}\text { Grandemultipara } \\
\qquad(>4)\end{array}$ & 1 & 2 & 0 & 0 \\
\hline \multicolumn{5}{|l|}{ IMT } \\
\hline Underweight & 0 & 0 & 1 & 2 \\
\hline Normal & 6 & 12 & 16 & 32 \\
\hline Overweight & 15 & 30 & 21 & 42 \\
\hline Obesitas & 29 & 58 & 12 & 12 \\
\hline Total & 50 & 100 & 50 & 100 \\
\hline
\end{tabular}

Tabel 2 memperlihatkan dari total 50 orang responden untuk masing-masing kelompok, didapatkan hasil bahwa ibu yang tidak menderita DMG tapi melahirkan bayi makrosomia pada kelompok kasus 
sebanyak 47 orang (94\%), sedangkan ibu yang tidak menderita DMG dan tidak melahirkan bayi makrosomia pada kelompok kontrol sebanyak 48 orang (98\%) (Tabel 2).

Pada Tabel 2 tersebut didapatkan nilai Odds Ratio sebesar 1,532 (CI 95\% 0,2459,857) dimana OR $>1$ sehingga dapat dikatakan bahwa diabetes mellitus gestasional merupakan faktor resiko dari makrosomia. Hasil uji chi-square memperlihatkan nilai $p=0,646(p>0,05)$ yang berarti tidak ada kaitan diabetes mellitus gestasional dengan makrosomia.

Tabel 2. Kaitan Makrosomia dan Diabetes Melitus Gestasional

\begin{tabular}{lcccc}
\hline Variabel & \multicolumn{3}{c}{ Makrosomia } \\
\cline { 2 - 5 } & $\begin{array}{c}\text { Kelompok } \\
\text { Kasus }\end{array}$ & $\begin{array}{c}\text { Kelompok } \\
\text { Kontrol }\end{array}$ \\
\hline Diagnosis DMG & $\mathrm{n}$ & $\%$ & $\mathrm{n}$ & $\%$ \\
\hline DMG & 3 & 6 & 2 & 4 \\
Tidak DMG & 47 & 94 & 48 & 96 \\
Total & 50 & 100 & 50 & 100 \\
\hline
\end{tabular}

\section{BAHASAN}

Umur ibu merupakan salah satu faktor yang dapat berkontribusi secara tidak langsung pada kejadian prediabetes/ diabetes mellitus gestasional. ${ }^{4}$ Tabel 1 memperlihatkan umur paling banyak pada kelompok kasus (yang melahirkan bayi makrosomia) ialah usia >35 tahun, sebaliknya pada kelompok kontrol (yang tidak melahirkan bayi makrosomia) usia tersebut yang paling sedikit. Pada hasil penelitian sebelumnya didapatkan hasil bahwa umur ibu hamil $\geq 35$ tahun beresiko 4,05 kali untuk menderita diabetes mellitus gestasional dibandingkan dengan umur ibu hamil < 35 tahun. ${ }^{4}$ Hal ini menunjukkan bahwa kebanyakan ibu hamil yang melahirkan bayi makrosomia pada kelompok kasus beresiko tinggi untuk menderita diabetes mellitus gestasional.

Pendidikan terakhir dari kelompok kasus yang terbanyak adalah SMA sebanyak 42 orang (84\%), sama seperti pada kelompok kontrol. Hal ini menunjukkan bahwa subjek memiliki pendidikan yang cukup tinggi. Pada penelitian yang dilakukan oleh Rajesh et al (2011) didapatkan hasil bahwa terdapat peningkatan prevalensi diabetes mellitus gestasional yang signifikan dengan meningkatnya tingkat pendidikan sedangkan pada studi lainnya Yang et al tidak menemukan hubungan antara diabetes mellitus gestasional dan pendidikan pada wanita hamil di Cina. ${ }^{6}$

Faktor risiko melahirkan bayi makrosomia antara lain obesitas, diabetes mellitus gestasional, diabetes mellitus tipe 2 , gestasi postterm, multiparitas, orang tua berperawakan besar, riwayat makrosomia sebelumnya. ${ }^{7}$ Untuk status pernikahan pada Tabel 1 kebanyakan ibu menikah baik pada kelompok kasus maupun kelompok kontrol. Status pernikahan sendiri bukan merupakan faktor resiko.

Untuk paritas pada dapat dilihat bahwa multiparitas (2-4) lebih banyak ditemukan pada kelompok kasus daripada kelompok kontrol. Paritas yang lebih tinggi telah ditemukan terkait dengan prevalensi yang lebih tinggi dari GDM dalam beberapa studi. Namun dalam penelitian yang dilakukan oleh Rajesh et al (2011) hubungan ini tidak ditemukan signifikan secara statistik. Pada penelitian lainnya Jang et al menemukan rasio yang lebih besar pada wanita dengan diabetes mellitus gestasional dalam kelompok dengan paritas $>2$, dibandingkan dengan primipara tetapi setelah mengontrol usia, pra-kehamilan BMI, tinggi badan, riwayat keluarga diabetes mellitus dan berat badan selama kehamilan, hasilnya tidak signifikan secara statistik. $^{6}$

Obesitas jelas terkait dengan diabetes dan diantara perempuan yang menderita diabetes, obesitas dan kehamilan postterm secara bersamaan memiliki insiden makrosomia sebesar 5-15 \%. ${ }^{7}$ Pada Tabel 1 dapat dilihat bahwa ibu yang melahirkan bayi makrosomia pada kelompok kasus paling banyak menderita obesitas dan overweight dibandingkan dengan kelompok kontrol. Menurut penelitian yang dilakukan oleh Salvatore et al (2013) wanita dengan obesitas 1,7 kali berisiko lebih tinggi 
melahirkan bayi makrosomia dibandingkan dengan wanita yang memiliki berat badan normal (OR 1,7 CI 95\% 1,4-2,2; $\mathrm{p}<0,001){ }^{8}$ Rajesh et al. ${ }^{6}$ juga menemukan bahwa diabetes mellitus gestasional ditemukan lebih tinggi pada wanita dengan IMT yang lebih tinggi dan berat badan sebelum kehamilan yang lebih tinggi. Hal ini menunjukkan bahwa pada kelompok ibu yang melahirkan bayi makrosomia banyak yang memiliki faktor resiko untuk melahirkan bayi makrosomia dan menderita diabetes mellitus gestasional.

Diabetes mellitus gestasional merupakan salah satu faktor risiko dari makrosomia. Insiden diabetes pada ibu meningkat sejalan dengan meningkatnya berat badan lahir bayi makrosomia yaitu > 4000 gram, namun hanya sebagian kecil dari makrosomia yang terkait dengan diabetes. $^{7}$ Hal ini sesuai dengan hasil penelitian pada Tabel 2 dimana hanya 3 orang $(6 \%)$ saja yang menderita diabetes mellitus gestasional dari 50 ibu yang melahirkan bayi makrosomia.

Pada Tabel 2 tersebut dapat dilihat bahwa 47 orang (94\%) yang melahirkan bayi makrosomia tidak menderita diabetes mellitus gestasional. Namun pada Tabel 1 juga bisa kita lihat bahwa sebagian besar ibu yang melahirkan bayi makrosomia kebanyakan memiliki faktor resiko selain diabetes mellitus gestasional, di antaranya obesitas dan multiparitas. Hal ini menunjukkan bahwa pada kelompok kasus obesitas dan multiparitas lebih banyak berperan dalam patogenesis makrosomia dibandingkan dengan diabetes mellitus gestasional. Pada kelompok kontrol terdapat 2 orang (4\%) ibu yang menderita diabetes mellitus gestasional namun tidak melahirkan bayi makrosomia. Hal ini mungkin disebabkan oleh banyaknya faktor resiko lain yang dapat menyebabkan makrosomia selain diabetes mellitus gestasional. Insidensi diabetes mellitus yang melahirkan bayi makrosomia juga hanya sebagian kecil saja. ${ }^{7}$

Berdasarkan hasil Tabel 2 di atas didapatkan nilai Odds Ratio 1,532 (CI 95\% 0,245-9,857) dimana OR $>1$ sehingga dapat dikatakan bahwa diabetes mellitus gestasional merupakan faktor resiko dari makrosomia. Hal ini sesuai dengan penelitian yang dilakukan oleh Lawlor et al. ${ }^{9}$ dimana makrosomia pada diabetes mellitus gestasional memiliki OR 5.50 (CI $95 \% 1,18$ - 10,30). Begitu pula dengan penelitian dari Salvatore et al. $^{8}$ makrosomia dan diabetes mellitus gestasional memiliki sebesar OR 2.1, 95\% CI $1.5-3.0 .^{8}$

Hasil uji chi-square memperlihatkan nilai $p=0,646(p>0,05)$ yang berarti tidak ada kaitan diabetes mellitus gestasional dengan makrosomia. Hasil ini tidak sesuai dengan hasil penelitian Stotland et al. ${ }^{10}$ bahwa bayi berjenis kelamin laki-laki, multiparitas, usia maternal 30-40 tahun, ras kulit putih, diabetes dan umur kehamilan $>41$ minggu berhubungan signifikan dengan makrosomia $(p<0,001) .{ }^{10}$ Hal ini mungkin disebabkan oleh adanya faktorfaktor lain yang ikut berpengaruh terhadap risiko ibu melahirkan bayi makrosomia yang terdapat dalam penelitian ini yaitu obesitas dan multiparitas.

Pada penelitian ini jumlah ibu yang melahirkan makrosomia sekaligus menderita DMG sangat sedikit sehingga didapatkan hasil tidak ada kaitan yang signifikan secara statistik antara diabetes mellitus gestasional dan makrosomia. Kadar GDS ibu yang melahirkan bayi makrosomia juga hanya meningkat sedikit dari kriteria diagnosis diabetes mellitus gestasional, yaitu $>200 \mathrm{mg} / \mathrm{dL}$. Jumlah sampel yang terbatas pada periode satu tahun saja merupakan kendala pada penelitian ini oleh karena itu diharapkan pada penelitian lanjutan mengenai hal ini dilakukan dengan jumlah populasi yang lebih besar lagi.

\section{SIMPULAN}

Dari hasil penelitian dapat disimpulkan bahwa tidak terdapat kaitan antara makrosomia dengan diabetes mellitus gestasional $(\mathrm{p}=0,646)$. Diabetes mellitus gestasional merupakan faktor resiko melahirkan bayi makrosomia dengan OR 1,532 (CI 95\%; 0,245-9,857). Faktor 
risiko diabetes mellitus gestasional dan makrosomia juga banyak terdapat pada subjek antara lain usia $>35$ tahun, obesitas dan multiparitas.

\section{SARAN}

Obesitas dan multiparitas merupakan faktor risiko terhadap kejadian makrosomia maka disarankan agar ibu hamil melakukan pengaturan pola makan sebelum dan saat kehamilan berlangsung serta melakukan kontrol kelahiran dengan $\mathrm{KB}$ untuk menghindari peningkatan risiko makrosomia seiring dengan tingginya paritas.

Usia >35 tahun merupakan faktor resiko kejadian DMG, sehingga ibu disarankan juga untuk mengontrol kadar gula darah secara rutin.

\section{DAFTAR PUSTAKA}

1. Cunningham FG, Levono KJ, Bloom SL, Hauth JC, Rouse DJ, Spong CY. Williams Obstetric (23rd ed.). The McGraw-Hill Companies, Inc, 2010; p. 863,872-4.

2. Trisnasiwi A, Trisnawati Y, Sumarni. Pengetahuan Ibu Hamil Tentang Makrosomia Dengan Pola Nutrisi Selama Hamil Tahun 2011. Bidan Prada J Ilmiah Kebidanan. 2012;3(2):11-4.

3. Wintry Y. Hubungan Pengetahuan Dan Sikap Ibu Hamil Tentang Bayi Makrosomia di Klinik Bersalin Niar Jalan Balai Desa Kecamatan Medan Patumbak Tahun 2011 [Skripsi]. Medan: Universitas Sumatera Utara, 2011. Accessed online 2013 Sept 16. Available from: repository.usu.ac.id.

4. Ifan PS, Wahiduddin, Dian S. Faktor Risiko Kejadian Pradiabetes/Diabetes Mellitus Gestasional di RSIA Sitti Khadijah I Kota Makassar [Skripsi]. Makassar: Universitas Hasanuddin. 2013.
5. Moore TR, et al. Diabetes Mellitus And Pregnancy. Medscape [homepage on the Internet]. Nodate [cited 2013 Sept 17]. Available from emedicine.medscape.com/article/12754 7-overview\#showall.

6. Rajesh R, et al. Prevalence Of Gestational Diabetes Mellitus \& Associated Risk Factors At A Tertiary Care Hospital In Haryana. Indian J Med. 2013;137:72833.

7. Cunningham, Kenith JL, Steven LB, John CH, Dwight JR. Catherine YS. Williams Obstetrics (23rd ed.). McGraw-Hills Company. 2010;p.873,1128.

8. Salvatore et al. The role of gestational diabetes, pre-pregnancy body mass index and gestational weight gain on the risk of newborn macrosomia: results from a prospective multicentre study. Jurnal BMC Pregnancy and Childbirth. 2014 [cited 2014 Jan 12];14:23. Available from http://www.biomedcentral.com/14712393/14/23.

9. Lawlor DA, Fraser A, Lindsay RS, Ness A, Dabelea D, Catalano $P$, et al. Association of existing diabetes, gestational diabetes and glycosuria in pregnancy with macrosomia and offspring body mass index, waist and fat mass in later childhood: findings from a prospective pregnancy cohort. Jurnal Diabetologia [homepage on the Internet]. 2010 [cited 2014 Jan 12];53(1):89-97. Available from http://www.ncbi.nlm.nih.gov/pubmed/1 9841891.

10. Stotland NE, Caughey AB, Breed EM, Escobar GJ. Risk factors and obstetric complications associated with macrosomia [serial online]. Int $\mathrm{J}$ of Gynecology \& Obstetrics. 2004 [cited 2014 Jan 12];87(3):220-6. Available from: www.ijgo.org/article/S00207292(04)00335-2/abstract. 